\title{
Distinct Levels of Dopamine Denervation Differentially Alter Striatal Synaptic Plasticity and NMDA Receptor Subunit Composition
}

\author{
Vincent Paillé, ${ }^{1 *}$ Barbara Picconi, ${ }^{1 *}$ Vincenza Bagetta, ${ }^{1}$ Veronica Ghiglieri, ${ }^{1}$ Carmelo Sgobio, ${ }^{1}$ \\ Massimiliano Di Filippo, ${ }^{1,4}$ Maria T. Viscomi, ${ }^{1}$ Carmela Giampà, ${ }^{1}$ Francesca R. Fusco, ${ }^{1}$ Fabrizio Gardoni, ${ }^{2}$ \\ Giorgio Bernardi, ${ }^{1}$ Paul Greengard, ${ }^{3}$ Monica Di Luca, ${ }^{2}$ and Paolo Calabresi ${ }^{1,4}$ \\ ${ }^{1}$ Fondazione Santa Lucia, Instituto di Ricovero e Cura a Carattere Scientifico, 00179 Rome, Italy, ${ }^{2}$ Center of Excellence of Neurodegenerative Diseases, \\ University of Milan, 20133 Milan, Italy, ${ }^{3}$ Rockefeller University, Laboratory of Molecular and Cellular Neuroscience, New York, New York 10065, and \\ ${ }^{4}$ Clinica Neurologica, University of Perugia, Ospedale S. Maria della Misericordia, 06156 Perugia, Italy
}

A correct interplay between dopamine (DA) and glutamate is essential for corticostriatal synaptic plasticity and motor activity. In an experimental model of Parkinson's disease (PD) obtained in rats, the complete depletion of striatal DA, mimicking advanced stages of the disease, results in the loss of both forms of striatal plasticity: long-term potentiation (LTP) and long-term depression (LTD). However, early PD stages are characterized by an incomplete reduction in striatal DA levels. The mechanism by which this incomplete reduction in DA level affects striatal synaptic plasticity and glutamatergic synapses is unknown. Here we present a model of early PD in which a partial denervation, causing mild motor deficits, selectively affects NMDA-dependent LTP but not LTD and dramatically alters NMDA receptor composition in the postsynaptic density. Our findings show that DA decrease influences corticostriatal synaptic plasticity depending on the level of depletion. The use of the TAT2A cell-permeable peptide, as an innovative therapeutic strategy in early PD, rescues physiological NMDA receptor composition, synaptic plasticity, and motor behavior.

\section{Introduction}

Parkinson's disease (PD) is a neurodegenerative disorder characterized by a massive degeneration of the dopaminergic neurons of the substantia nigra pars compacta $(\mathrm{SNc})$. The progressive degeneration of nigrostriatal terminals leads to a depletion of dopamine (DA) in the striatum altering basal ganglia functioning, and it is subsequently responsible for most of the PD motor symptoms, such as akinesia, rigidity, and tremor (Fearnley and Lees, 1991; Lang and Lozano, 1998). A complete DA denervation, as observed in advanced PD, induces maladaptive plasticity (Calabresi et al., 2007), alteration of striatal dendritic spines (Anglade et al., 1996; Day et al., 2006), and changes of glutamatergic signaling (Betarbet et al., 2004; Picconi et al., 2004). Modifications of the

\footnotetext{
Received April 26, 2010; revised July 16, 2010; accepted July 26, 2010.

This work was supported by the European Community Contract 222918 (Restorative Plasticity at Corticostriatal Excitatory Synapses) FP7 Thematic Priority HEALTH (P.C., M.D.L.), CPADS Grant 217902 (M.D.L), Progetto Strategico 2007 (P.C., B.P.), Progetti Finalizzati 2006 -2008 (P.C., B.P.), Progetti Finalizzati Multicentrici Programma Neuroscienze Compagnia di San Paolo (P.C.), Progetto Ministero della Salute, Young Italian Researchers Grants 2008 (B.P.), and Fondation de la Recherce Médicale (V.P.). We thank Fulvio Florenzano and Marco Molinari from the Fondazione Santa Lucia in Rome for technical advice.

The authors have nothing to disclose.

*V.P. and B.P. contributed equally to this work.

Correspondence should be addressed to Dr. Paolo Calabresi, Clinica Neurologica, Università di Perugia, Dipartimento di Specialità Medico Chirurgiche e Sanità Pubblica, Ospedale S. Maria della Misericordia, 06156 Perugia, Italy. E-mail: calabre@unipg.it.

V. Paillés present address: Dynamique et Physiopathologie des Réseaux Neuronaux, Inserm, Unité 667, Collège de France, 75231 Paris Cedex 05, France.

DOI:10.1523/JNEUROSCI.2149-10.2010

Copyright $\odot 2010$ the authors $\quad 0270-6474 / 10 / 3014182-12 \$ 15.00 / 0$
}

NMDA receptor (NMDAR) complex within the postsynaptic density (PSD) occur as a consequence of an altered coupling between NMDA receptor subunits and their interacting elements, i.e., members of the membrane-associated guanylate kinase (MAGUK) protein family (Gardoni et al., 2006). All these processes have been identified as critical mechanisms underlying the expression of motor symptoms after DA denervation. Accordingly, electrophysiological studies have shown a loss of both long-term potentiation (LTP) and long-term depression (LTD) at corticostriatal synapses after a complete dopaminergic denervation, indicating that the integrity of the nigrostriatal dopaminergic pathway is of crucial importance for the induction of striatal long-lasting synaptic changes (Calabresi et al., 1992, 2000a; Centonze et al., 1999; Tang et al., 2001; Picconi et al., 2003; Kreitzer and Malenka, 2007).

Early clinical symptoms of PD are only detected when $>70 \%$ of DA neurons are lost (Fearnley and Lees, 1991). A reliable model of early PD characterized by a DA lowering close to this threshold is of key importance to understand the molecular and synaptic changes underlying this early stage and find new therapeutic strategies to treat early phases of the disease. At this stage, the clinical response to DA replacement by L-3,4-dihydroxyphenylalanine (L-DOPA) treatment is optimal. However, clinicians try to avoid this treatment in the early phase of the disease because the long-term use of this DA precursor in several patients leads to a loss of efficacy in the later phases and anticipates L-DOPA-induced dyskinesia (Lang and Lozano, 1998). Considering the close interaction between NMDA receptors and DA transmission, it 
would be of great importance to test, in a model of early PD, an alternative therapeutic strategy targeting NMDA receptor signaling rather than DA replacement.

To this end, we have used an experimental approach able to model DA denervation in both the advanced and the early stages of PD. This approach should be valuable in identifying new targets for pharmacological intervention and thus helping in covering unmet needs of PD therapy.

\section{Materials and Methods}

6-Hydroxydopamine hydrochloride nigrostriatal injection

Ninety-eight male Wistar rats were deeply anesthetized with chloral hydrate (400 $\mathrm{mg} \cdot \mathrm{ml}^{-1} \cdot \mathrm{kg}^{-1}$ ) and were injected into the medial forebrain bundle (MFB) (at the following coordinates: anteroposterior, $-4.4 \mathrm{~mm}$; lateral, $+1.2 \mathrm{~mm}$; ventrodorsal, $-7.8 \mathrm{~mm}$ ) with $12 \mu \mathrm{g}$ of 6-hydroxydopamine hydrochloride (6-OHDA) $(3 \mu \mathrm{g} / 4 \mu \mathrm{l}$ in saline containing $0.1 \%$ ascorbic acid) and with $3 \mu \mathrm{g}$ of 6-OHDA (50 rats) at a rate of $0.38 \mu \mathrm{l} / \mathrm{min}$ (Paxinos et al., 1985). Twenty-seven rats were injected only with vehicle at the same coordinates. Fifteen days later, the rats were tested with $0.05 \mathrm{mg} / \mathrm{kg}$ subcutaneous apomorphine, and contralateral turns to the lesion were counted for $40 \mathrm{~min}$. The operated rats were split in three groups according to the number of turns (Schwarting and Huston, 1996). The rats that showed $>200$ contralateral turns were put in the group of full-lesion (FL) animals, the rats showing $>10$ but $<100$ contralateral turns were put in the partial-lesion (PL) group, and the rats showing $0-10$ turns were considered not lesioned. After lesion, the rats were used for biochemical, electrophysiological, and behavioral experiments. The severity of the lesion was quantified afterward by striatal and nigral tyrosine hydroxylase $(\mathrm{TH})$ immunohistochemistry.

\section{Motor deficit quantification}

Each animal was systematically handled on a regular basis (i.e., taken by hand from its cage, put on a table, gently touched, moved from one place to another, and then, after several minutes of continuous contact with the human hand, returned to its home cage) for several days before the first assessment.

Forelimb akinesia was assessed using a modified version of the stepping test (Paillé et al., 2007). Briefly, the experimenter firmly suspended the rat's hindquarters while it supported its weight on its forelimbs. Then the experimenter moved the rat backward along the table $(0.9 \mathrm{~m}$ in $5 \mathrm{~s})$ three times consecutively per session. All the sessions were video recorded to allow the number of adjusting steps to be counted afterward by an investigator blinded to the state of the rat (i.e., 6-OHDA-lesioned or sham-operated). For each session, the total score calculated was the sum of the number of adjusting steps observed in the three tests (for the contralateral paw). The sessions took place between 2:30 P.M. and 4:30 P.M. 1 week before surgery and 2 weeks after surgery (just before the apomorphine-induced rotation test).

The peptide TAT2A was injected intraperitoneally at $1 \mathrm{ml} / \mathrm{kg}$ once a day at a dose of $3 \mathrm{nmol} / \mathrm{g}$ (Aarts et al., 2002) on sham-operated, PL, and FL rats for $5 \mathrm{~d}$. The stepping test was quantified the day before the first injection and the last day. The $\mathrm{D}_{1}$ agonist SKF38393 (2,3,4,5-tetrahydro7,8-dihydroxy-1-phenyl- $1 \mathrm{H}$-3-benazepine $\mathrm{HCl}$ ) was injected intraperitoneally at a dose of $2 \mathrm{mg} \cdot \mathrm{ml}^{-1} \cdot \mathrm{kg}^{-1}$ one time $5 \mathrm{~min}$ before the stepping test on PL rats (Olsson et al., 1995). The treated rats were then killed for electrophysiological and Western blot (WB) analysis.

\section{Electrophysiology}

Sharp electrode recordings. Corticostriatal coronal slices $(270-300 \mu \mathrm{m}$ thickness) were prepared from sham-operated animals and from PL and FL parkinsonian rats. A single slice was transferred to a recording chamber and submerged in a continuously flowing artificial CSF (ACSF) solution $\left(32^{\circ} \mathrm{C}, 2 \pm 3 \mathrm{ml} / \mathrm{min}\right)$ gassed with $95 \% \mathrm{O}_{2} / 5 \% \mathrm{CO}_{2}$. The composition of the ACSF solution was as follows (in $\mathrm{mM}$ ): $126 \mathrm{NaCl}, 2.5$ $\mathrm{KCl}, 1.2 \mathrm{MgCl}_{2}, 1.2 \mathrm{NaH}_{2} \mathrm{PO}_{4}, 2.4 \mathrm{CaCl}_{2}, 11$ glucose, and $25 \mathrm{NaHCO}_{3}$. Intracellular current-clamp recordings were performed to study the synaptic plasticity of striatal spiny neurons (Calabresi et al., 1992; Centonze et al., 1999; Picconi et al., 2003). For synaptic stimulation, bipolar electrodes were used and were located in the white matter between the cortex and the striatum. The intracellular recording electrodes were filled with 2 м KCl (30-60 M $\Omega$ ). An AxoClamp 2B amplifier (Molecular Devices) was used for recordings in current-clamp mode. The head-stage signal was continuously monitored on a separate oscilloscope. Traces were displayed on an oscilloscope and stored on a digital system (pClamp9; Molecular Devices). $\mathrm{Mg}^{2+}$ ions were omitted from the medium to better disclose the NMDA-mediated component of the evoked EPSP. Under this experimental condition, high-frequency stimulation (HFS) (three trains, $3 \mathrm{~s}$ duration, $100 \mathrm{~Hz}$ frequency, $20 \mathrm{~s}$ intertrain interval) of corticostriatal fibers was used as an LTP-inducing protocol. The same HFS protocol in the presence of $1.2 \mathrm{mM} \mathrm{Mg}^{2+}$ was used to induce LTD in striatal spiny neurons. The observed changes in synaptic plasticity were not associated with major alterations of the measured intrinsic membrane properties of the recorded spiny neurons. In fact, both resting membrane potential (sham, $n=14,87 \pm 7 \mathrm{mV}$; PL, $n=18,89 \pm 3 \mathrm{mV}$; $\mathrm{FL}, n=16,90 \pm 6 \mathrm{mV}$ ) and input resistance (sham, $n=16,34 \pm 3 \mathrm{M} \Omega$; PL, $n=19,33 \pm 6 \mathrm{M} \Omega$; FL, $n=20,30 \pm 4 \mathrm{M} \Omega$ ) were similar in the three experimental groups.

Quantitative data on EPSP modifications induced by tetanic stimulation are expressed as a percentage of the controls, the latter representing the mean of responses recorded during a stable period (15-20 min) before the tetanus. Values given in the text and in the figures are mean \pm SE of changes in the respective cell populations.

Whole-cell recordings. Coronal brain slices (240-270 $\mu \mathrm{m}$ thickness) were transferred to a submerged recording chamber, perfused $(2-3 \mathrm{ml} /$ min) with oxygenated ACSF, and visualized with $10 \times$ and $40 \times$ waterimmersion objectives (Nikon) using standard infrared and differential interference contrast microscopy. Whole-cell recordings were performed using $1.5 \mathrm{~mm}$ external diameter borosilicate pipettes. For both current- and voltage-clamp recordings, electrodes (2.8-5 M $\Omega$ ) were filled with a solution containing the following (in $\mathrm{mM}$ ): 125 potassium gluconate, $15 \mathrm{KCl}, 0.04$ EGTA, 12 HEPES, $2 \mathrm{MgCl}_{2}, 4 \mathrm{MgATP}$, and 0.4 $\mathrm{Na}_{2} \mathrm{GTP}$, adjusted to $\mathrm{pH} 7.3$ with $\mathrm{KOH}$. Glutamatergic responses were evoked in striatal neurons with a tungsten bipolar stimulating electrode placed in the white matter between cortex and striatum or in the cortex close to the corpus callosum. Single stimuli were delivered at $0.1 \mathrm{~Hz}$. These responses were observed in medium spiny neurons as EPSPs in current-clamp experiments or as EPSCs in voltage-clamp experiments. In voltage-clamp experiments, neurons were held at -70 or $-80 \mathrm{mV}$. For LTP experiments, $\mathrm{Mg}^{2+}$ ions were omitted from the bath solution to release the NMDA receptor-mediated component of the corticostriatal glutamatergic transmission. Under these conditions, HFS (three trains of 300 stimuli at $100 \mathrm{~Hz}$, delivered at $20 \mathrm{~s}$ interval) of corticostriatal fibers was used to induce LTP, while the medium spiny neuron was recorded in current-clamp mode; during such HFS, the stimulation intensity was transiently increased to suprathreshold levels. For LTD induction, we used similar HFS trains, but the slice was bathed in control ACSF; in voltage-clamp experiments, the neurons were always maintained at the holding potential, and the intensity of stimulation was not increased during HFS. All the experiments were conducted in the continuous presence of the $\mathrm{GABA}_{\mathrm{A}}$ antagonist bicuculline $(30 \mu \mathrm{M})$. In some experiments, performed in voltage-clamp mode (supplemental Fig. 1, available at www.jneurosci.org as supplemental material), glass electrodes $(2.8-5$ $\mathrm{M} \Omega$ ) were filled with a solution containing the following (in $\mathrm{mM}$ ): 120 $\mathrm{CsMeSO}_{3}, 15 \mathrm{CsCl}, 8 \mathrm{NaCl}, 0.2$ EGTA, 10 HEPES, 2 Mg-ATP, 0.3 Na-GTP, 10 tetraethylammonium, and 5 QX-314 [N-(2,6-dimethylphenylcarbamoylmethyl)triethylammonium bromide], adjusted to $\mathrm{pH} 7.2$ with $\mathrm{CsOH}$. Excitatory synaptic currents were evoked with a saline-filled glass pipette placed in the corpus callosum or in the cortex close to the white matter. After a stable evoked EPSC recording had been maintained at least for $10 \mathrm{~min}$, LTD was induced by HFS. During the HFS protocol, the neurons were depolarized from holding potential to $0 \mathrm{mV}$ (Choi and Lovinger, 1997; Wang et al., 2006; Kreitzer and Malenka, 2007). These experiments were conducted in the continuous presence of bicuculline at $30 \mu \mathrm{M}$ and the NMDA receptor antagonist 2-amino5-phosphonopentanoic acid (AP-5) at $30 \mu \mathrm{M}$.

Analysis of NMDA-NR2A EPSC and of NMDAR/AMPAR ratio. Whole-cell recordings were performed using electrodes (3-6.0 M $\Omega$ ) filled with internal solution containing the following (in $\mathrm{mM}$ ): $120 \mathrm{Cs}-$ $\mathrm{MeSO}_{3}, 15 \mathrm{CsCl}, 8 \mathrm{Nacl}$, 0.2 EGTA, 10 HEPES, 2 Mg-ATP, 0.3 Na-GTP, 
10 tetraethylammonium, and 5 QX-314, adjusted to $\mathrm{pH} 7.2$ with $\mathrm{CsOH}$. The input resistance was monitored online with a $5 \mathrm{mV}$ depolarizing step $(50 \mathrm{~ms})$ given just after every afferent stimulus. A bipolar stimulating electrode has been placed $100-300 \mu \mathrm{m}$ rostral to the recording electrode and has been used to stimulate excitatory afferents at $0.1 \mathrm{~Hz}$. Neurons were voltage clamped at -70 and $+40 \mathrm{mV}$ to record, respectively, AMPAR- and NMDAR-mediated EPSCs. All experiments were performed in the presence of picrotoxin $(50 \mu \mathrm{M})$. NMDA EPSCs were pharmacologically isolated at $+40 \mathrm{mV}$ by the application of the AMPA antagonist 6-cyano-7-nitroquinoxaline-2,3-dione (CNQX) $(10 \mu \mathrm{M})$, whereas the NMDAR-NR2A component was obtained by applying ifenprodil at 10 $\mu \mathrm{M}$ after a stable recording of the NMDA component. For the experiments with TAT2A, the peptide was applied for $10 \mathrm{~min}$ after a stable recording of the NMDA-NR2A isolated component, and the amplitude of reduction was then measured as percentage compared with the control levels preceding TAT2A application. The NMDAR/AMPAR ratio was calculated by dividing the peak NMDAR-mediated EPSCs by the AMPAR-mediated EPSCs. Similarly, the NMDA-NR2A/AMPAR ratio was calculated by dividing NMDA-NR2A-mediated EPSCs by the AMPAR-mediated EPSCs. The following parameters were determined for averaged EPSCs in NMDAR/AMPAR experiments: peak amplitudes, decay time constants, and weighted $\tau\left(\tau_{\mathrm{W}}\right)$. All data are presented as mean \pm SE. The decay time constants were fit with a double-exponential equation: $I(t)=I_{\mathrm{f}} \times \exp \left(-t / \tau_{\mathrm{f}}\right)+I_{\mathrm{s}} \times \exp \left(-t / \tau_{\mathrm{s}}\right)$, where $I_{\mathrm{f}}$ is the amplitude of the fast component, $I_{\mathrm{s}}$ is the amplitude of the slow component, and $\tau_{\mathrm{f}}$ and $\tau_{\mathrm{s}}$ are the fast and slow time constants, respectively. Weighted time constants were calculated using the following equation: $\tau_{\mathrm{w}}=\left[I_{\mathrm{f}} /\left(I_{\mathrm{f}}\right.\right.$ $\left.\left.+I_{\mathrm{s}}\right)\right] \times \tau_{\mathrm{f}}+\left[\left(I_{\mathrm{s}} /\left(I_{\mathrm{f}}+I_{\mathrm{s}}\right)\right] \times \tau_{\mathrm{s}}\right.$ (Stocca and Vicini, 1998).

Recordings in whole-cell patch clamp were made using Multiclamp $700 \mathrm{~B}$ (Molecular Devices) and were acquired at $10 \mathrm{kHz}$ using pClamp10 software and a data acquisition unit (Digidata 1440A; Molecular Devices). Input resistances and injected currents were monitored throughout the experiments. Variations of these parameters $>20 \%$ lead to the rejection of the experiment.

Drugs. For in vitro electrophysiological recordings, drugs were applied by diluting them in Krebs' solution to the final concentration and by switching the perfusion from control to drug-containing solution. AP-5, CNQX, ifenprodil hemitartrate, picrotoxin, and L-sulpiride were from Tocris Cookson. Apomorphine hydrochloride, (-)-bicuculline methiodide, chloral hydrate, 6-OHDA, and SKF38393 hydrochloride were from Sigma-Aldrich. TAT2A and TAT2A-SDV peptides were kindly provided by Xigen.

Immunohistochemistry. After recording, the striatal sections were kept in $4 \%$ paraformaldehyde for $1 \mathrm{~d}$ and finally stored in $25 \%$ phosphate buffer (PB) sucrose for $24-48 \mathrm{~h}$ before cutting. Forty-micrometer-thick coronal sections were cut on a microtome (Microm) and collected in sequence in 24 -well plates containing $1 \mathrm{ml}$ of $\mathrm{PB}$. The $\mathrm{SNc}$ were cut in sequence following the same protocol.

Striatum sections were incubated overnight in a rabbit anti-TH (1:500; Santa Cruz Biotechnology), then immersed in a 1:500 dilution of biotinylated anti-rabbit IgG raised in donkey (Jackson ImmunoResearch), and transferred to a Vectastain ABC kit, Vector/PBS for $1 \mathrm{~h}$ (Vector Laboratories); $3,3^{\prime}$-diaminobenzidine served as chromogen in the subsequent visualization reaction. $\mathrm{SNc}$ sections were processed free floating for $\mathrm{TH}$ and neuron-specific nuclear antigen $(\mathrm{NeuN})$ double immunofluorescence. Sections were incubated with a mixture of the following antibodies: mouse anti-NeuN (1:200; IgM; Millipore Bioscience Research Reagents) and rabbit anti-TH (1:500; Santa Cruz Biotechnology). After incubation with primary antibodies and subsequent washing with $\mathrm{PB}$, sections were incubated in a mixture of secondary antibodies: cyanine 3 (Cy3)-conjugated donkey anti-mouse IgM and Cy2-conjugated donkey anti-rabbit IgG (1:100; Jackson ImmunoResearch). Sections were mounted in gelatin-coated slides, air-dried, and coverslipped with GEL/ MOUNT (Biomeda).

Striatal TH fiber density. The optical density values of the striatum sections were measured (using NIH Image J software) for each section analyzed and compared with those in homologous regions in intact side. The intensity of TH-immunoreactive (IR) fibers above a fixed threshold using entorhinal cortex for background subtraction was used to estimate striatal TH fiber density. Density was expressed as a percentage relative to the contralateral side.

Nigral DA neuron count. Stereology analyses software (Merkator; Explora Nova) was used to perform unbiased stereological counts of NeuN/ TH-IR cell bodies in the SNc using the optical fractionator method (McCoy et al., 2006). The boundary of SNc was defined according to previous anatomical demarcation in the rat (German and Manaye, 1993). For analysis, the treatment of the various brain sections was blinded to the observer. Cells were counted with a $60 \times$ objective $(0.85$ numerical aperture) using a Nikon Eclipse E600 microscope with a motorized stage $(x, y$, and $z)$. Random and systematic counting frames $(50 \times$ 50 spaced by $200 \mu \mathrm{m}$ ) were used; only neurons within the frame and focused in $50 \%$ of the thickness were counted on cryosections ( $40 \mu \mathrm{m}$ serial sections, one every six sections) obtained from $>27$ through the extent of SNc. A dopaminergic neuron was defined as a NeuN/THimmunoreactive cell body with a clearly visible unstained nucleus. THpositive cell loss in SNc was expressed as a percentage relative to the contralateral side of the brain.

Biocytin and Substance P confocal microscopy imaging. Medium spiny neurons were simultaneously filled with biocytin during recordings. Slices were then promptly placed in $4 \%$ paraformaldehyde in $0.1 \mathrm{M} \mathrm{PBS}$, $\mathrm{pH}$ 7.4. After overnight fixation at $4^{\circ} \mathrm{C}$, slice were cryoprotected in $10 \%$ sucrose and $20 \%$ glycerol in $0.1 \mathrm{M} \mathrm{PB}$ with $0.02 \%$ sodium azide for $48 \mathrm{~h}$ at $4^{\circ} \mathrm{C}$. After cryoprotection, slices were rinsed in PBS (three times, $10 \mathrm{~min}$ each) and placed in $0.3 \%$ Triton X-100 and $0.02 \%$ sodium azide for $3 \mathrm{~h}$ at room temperature. Sections (from each group) were then incubated with a primary antibody rabbit anti-Substance P (SP) (Immunological Science) to label the medium spiny projection neurons that are part of the "direct" basal ganglia circuit. The primary antiserum was used at a 1:400 concentration in $0.1 \mathrm{M} \mathrm{PB}$ containing $0.3 \%$ Triton X-100 and $0.02 \%$ sodium azide for $24 \mathrm{~h}$ at room temperature and $48 \mathrm{~h}$ at $4^{\circ} \mathrm{C}$. Sections were then rinsed three times for $15 \mathrm{~min}$ at room temperature and subsequently incubated with a mixture of goat anti-rabbit Cy2-conjugated secondary antibody (Jackson ImmunoResearch) and streptavidin-Cy3-conjugated secondary antibody (Sigma-Aldrich) for $2 \mathrm{~h}$ at room temperature. All the secondary antibodies were used at 1:200 concentration. Tissues were mounted on gelatin-coated slides, coverslipped with GEL/MOUNT, and examined under an epi-illumination fluorescence microscope (Carl Zeiss Axioskop 2), and a CLSM (Carl Zeiss LSM 510) was used to acquire all the images.

\section{Molecular study}

Antibodies. The following antibodies were used: polyclonal $\mathrm{D}_{1}$ receptor antibody was purchased from Abcam. Monoclonal $\alpha$ CaMKII antibody was purchased from Millipore Bioscience Research Reagents. Polyclonal SAP97 and SAP102 antibodies and monoclonal PSD-95 antibody were purchased from Affinity BioReagents. Monoclonal NR1 antibody was purchased from BD Biosciences Pharmingen. Polyclonal NR2A and NR2B antibodies were purchased from Zymed.

Western blot analysis. Striata were homogenized in $0.32 \mathrm{M}$ ice-cold sucrose containing the following (in mM): 1 HEPES, $1 \mathrm{MgCl}_{2}, 1$ EDTA, 1 $\mathrm{NaHCO}_{3}$, and 0.1 PMSF, pH 7.4, in the presence of a complete set of proteases inhibitors (Complete; Roche Diagnostics) and phosphatases inhibitors (Sigma). An aliquot of total homogenate fraction was stored for immunoprecipitation experiments. The homogenized tissue was centrifuged at $1000 \times g$ for $10 \mathrm{~min}$. The resulting supernatant (S1) was centrifuged at $13,000 \times g$ for 15 min to obtain a crude membrane fraction (P2 fraction). The pellet was resuspended in $1 \mathrm{~mm}$ HEPES plus Complete in a glass-glass Potter and centrifuged at $100,000 \times g$ for $1 \mathrm{~h}$. The pellet (P3) was resuspended in buffer containing $75 \mathrm{~mm} \mathrm{KCl}$ and $1 \%$ Triton $\mathrm{X}-100$ and centrifuged at $100,000 \times g$ for $1 \mathrm{~h}$. The supernatant was stored and referred as Triton X-100-soluble fraction (S4). The final pellet (P4) was homogenized in a glass-glass Potter in $20 \mathrm{~mm}$ HEPES. Then, an equal volume of glycerol was added, and this fraction, referred to Tritoninsoluble postsynaptic fraction (TIF), was stored at $-80^{\circ} \mathrm{C}$ until processing. TIF was used instead of the classical PSD because the amount of the starting material was very limited. The protein composition of this preparation was, however, carefully tested for the absence of presynaptic markers (i.e., synaptophysin) (Gardoni et al., 2001). Similar protein 
A

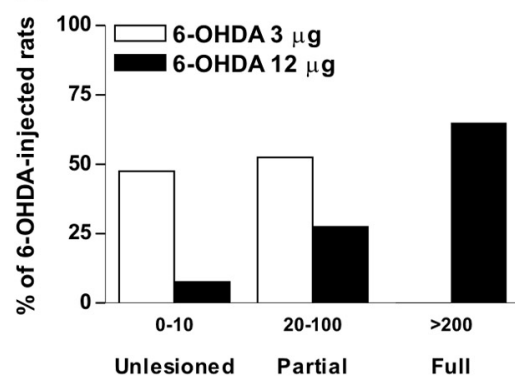

B

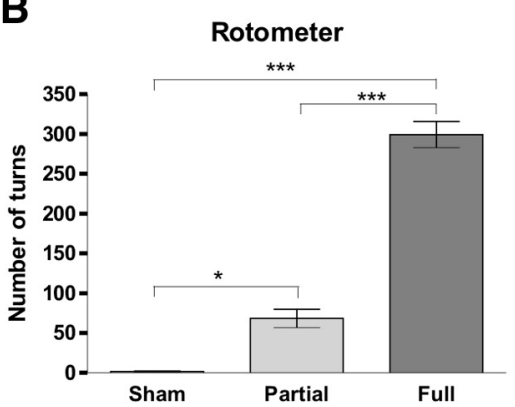

C

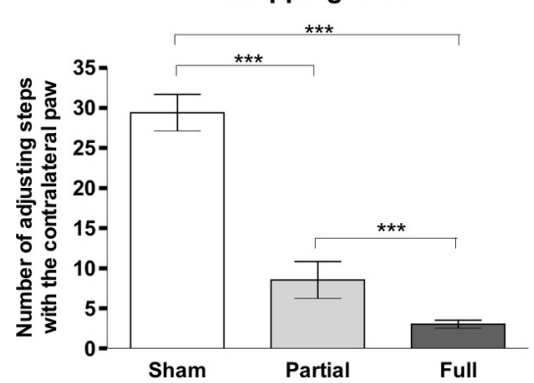

D

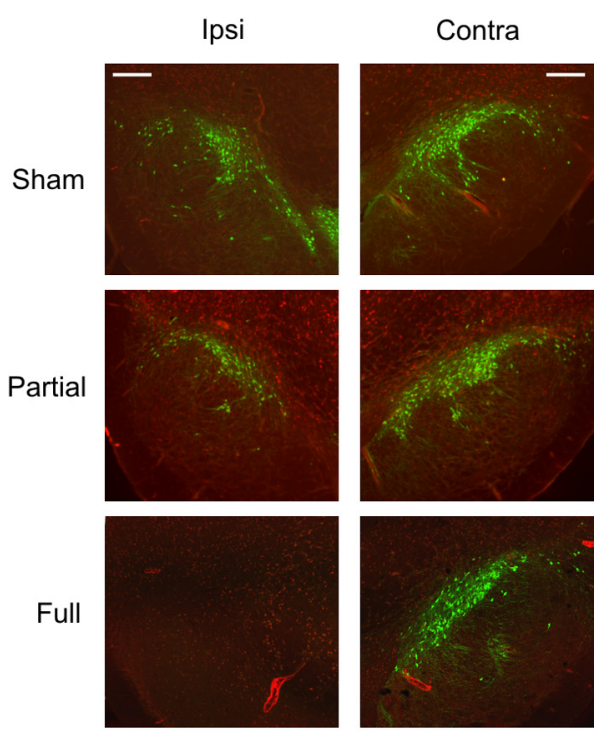

E

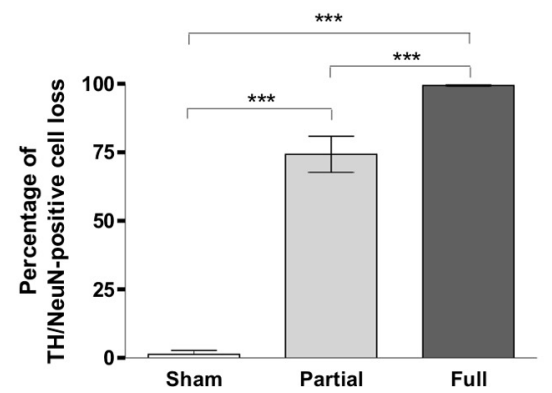

Figure 1. Behavioral and morphological characterization of animals showing a $\mathrm{PL}$, mimicking an early stage of $\mathrm{PD}$, and rats receiving an $\mathrm{FL}$, representing the late phase of the disease. $A$, Use of different doses of $6-0 \mathrm{HDA}$ ( 3 and $12 \mu \mathrm{g}$ of $6-0 \mathrm{HDA}, n=40$ rats for both doses) to obtain hemilateral partial or complete lesions of dopaminergic fibers in MFB. The injection of $3 \mu \mathrm{g}$ of $6-0 \mathrm{HDA}$ produced no lesion in $47.5 \%$ and a partial lesion in $52.5 \%$ of rats performing, respectively, $0-10$ and $20-100$ turns in the apomorphine-induced test. Conversely, the unilateral injection of $12 \mu \mathrm{g}$ of 6-0HDA produced no lesion in $7.5 \%$ of operated rats, a partial lesion in $27.5 \%$, and a full lesion in $65 \%$ of rats performing, respectively, $0-10,20-100$, and $>200$ turns/40 min. $B$, FL rats $(n=26)$, selected using rotometer turning behavior test, showed $>200$ turns in 40 min. PL rats $(n=32)$ performed $20-100$ turns, in $40 \mathrm{~min}$. Values were expressed as the group mean \pm SE with ${ }^{*} p<0.05,{ }^{* * *} p<0.001$. C, The forelimb akinesia, detected using a stepping test, of FL and PL animals, 2 weeks after lesion and before the apomorphine turning test, was significantly altered compared with sham-operated rats. Forelimb akinesia of FL rats was significantly different from the PL group. Values were expressed as the group mean \pm SE with ${ }^{* * *} p<0.001$. D, Representative sections of TH (green) and NeuN (red) double immunostaining in rats with sham, PL, and FL of the left SNc. Scale bars, $100 \mu \mathrm{m}$. Ipsi, Ipsilateral; Contra, contralateral. $\boldsymbol{E}$, Percentage of TH/NeuN-positive cell loss compared with contralateral side. The count was made blindly using the optical fractionator stereological method. The DA cell loss was still high in the SNc of PL animals but significantly different compared with FL. Values were expressed as the group mean $\pm \mathrm{SE}$ with ${ }^{* * *} p<0.001$ (FL, $n=7 ; \mathrm{PL}, n=10$; sham-operated, $n=10$ ).

yields were obtained in TIF purified from striata of all experimental groups, and the same amount of TIF protein was applied to SDS-PAGE and electroblotted for all samples. Nitrocellulose papers were blocked with 10\% albumin in Tris-buffered saline (TBS) and then incubated for $2 \mathrm{~h}$ at room temperature with the primary antibodies: NR1 (diluted 1:1000), NR2A (diluted 1:1000), NR2B (diluted 1: 1000), GluR1 (diluted 1:1000), PSD-95 (diluted 1:2000), SAP97 (diluted 1:1000), SAP102 (diluted 1:1000), $\alpha$ CaMKII (diluted 1:3000), and $\mathrm{D}_{1}$ (diluted $1: 1000$ ) in $3 \%$ albumin in TBS. After extensive rinsing in TBS/0.1\% Tween 20 , the nitrocellulose papers were then incubated with horseradish peroxidaseconjugated secondary antibodies [goat anti-rabbit, for polyclonal antibodies, diluted 1:10,000 (Pierce); goat antimouse, for monoclonal antibodies, diluted 1:20,000 (Pierce)], and then the antigen-antibody complex was revealed by enhanced chemiluminescence (ECL; GE Healthcare).
Immunoprecipitation experiments. Aliquots of striatal homogenates and TIF were incubated overnight at $4^{\circ} \mathrm{C}$ in buffer A, containing the following: $200 \mathrm{~mm} \mathrm{NaCl}, 10 \mathrm{~mm}$ EDTA, 10 $\mathrm{mM} \mathrm{Na} \mathrm{NPO}_{4}, 0.5 \% \mathrm{NP}-40$, and $0.1 \%$ SDS with antibodies against PSD-95, NR2A, or NR2B subunits of NMDA receptor. Protein A-agarose beads (Santa Cruz Biotechnology), washed in the same buffer, were added, and incubation continued for $2 \mathrm{~h}$. The beads were collected by centrifugation and washed five times with buffer A, sample buffer for SDSPAGE was added, and the mixture was boiled for $5 \mathrm{~min}$. Beads were pelleted by centrifugation, and supernatants were applied to $6 \%$ SDS-PAGE.

\section{Statistical analyses}

Statistical analyses of the electrophysiological experiments were done using a two-way ANOVA. If the interactions were significant, the tests were followed by Bonferroni's test for post hoc comparison. Statistical analyses of WB quantifications were performed according to one-way ANOVA, followed by Bonferroni's test for post hoc comparison. Motor behavior and immunohistochemistry quantifications were analyzed with an ANOVA test, followed by a Newman-Keuls post hoc test. Paired $t$ test was used for the analysis of the stepping test score before and after drug administration.

\section{Results}

"Full" versus "partial” DA denervation as distinct models of "advanced" and “early" PD

We obtained the unilateral nigral lesion by the injection of 6-OHDA in the ascending nigrostriatal pathway (Picconi et al., 2003; Höglinger et al., 2004). In particular, early versus advanced PD was modeled by using different doses of 6-OHDA ( $3 \mu \mathrm{g}$ of $6-\mathrm{OHDA}, n=40$ rats vs $12 \mu \mathrm{g}$ of 6-OHDA, $n=40$ rats) (Fig. $1 A$ ), inducing either PL or FL of dopaminergic fibers in MFB. Two weeks after the surgery, the apomorphine-induced rotation test was performed to distinguish between rats with partial versus full lesion of the ascending nigrostriatal pathway (Fig. $1 B$ ). In particular, rats with $>200$ turns in 40 min were considered to have up to $95 \%$ depletion of DA within the striatum (Schwarting and Huston, 1996) and in the A9 cell groups (Perese et al., 1989; Deumens et al., 2002) and were considered "fully lesioned", whereas rats performing $<100$ turns, but at least 20 turns, in $40 \mathrm{~min}$ were considered "partially lesioned" (Fig. $1 A, B,{ }^{\star} p<0.05$ sham-operated vs $\mathrm{PL},{ }^{* * *} p<0.001$ sham-operated vs FL and PL vs FL). According to motor behavior, the injection of $3 \mu \mathrm{g}$ of 6-OHDA produced no lesion in 19 of 40 animals $(47.5 \%)$ and a partial lesion in 21 of 40 rats $(52.5 \%)$ (Fig. 1A). No full lesions were observed in the group treated with the low dose of 6-OHDA. Conversely, the unilateral injection of $12 \mu \mathrm{g}$ of 6-OHDA resulted in no lesion in 3 of 40 animals (7.5\%), a partial lesion in 11 of 40 animals $(27.5 \%)$, and a full lesion in 26 of 40 rats $(65 \%)$ (Fig. $1 A)$. The homogeneity of the two dener- 
A

Sham

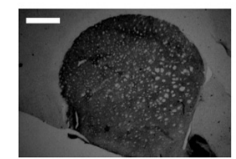

Partial

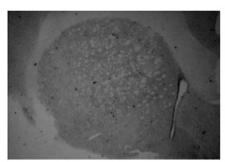

Full
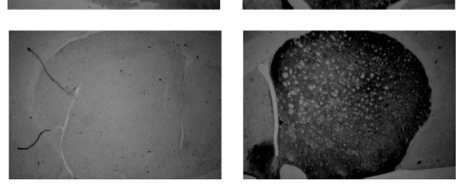

B

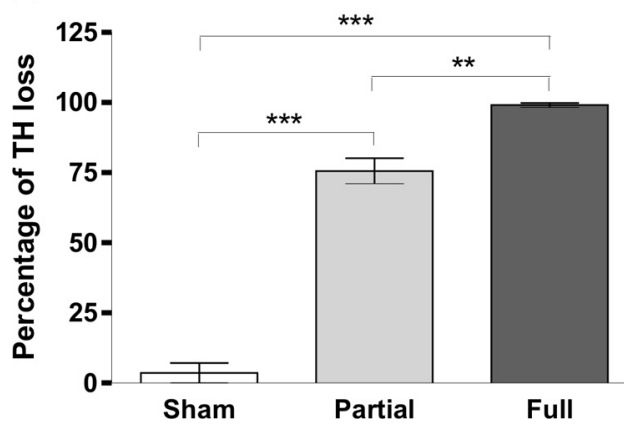

Figure 2. TH immunohistochemistry of the striatum from sham-operated, PL, and FL rats. $A$, Representative section of TH immunostaining in the striatum of sham-operated, $\mathrm{PL}$, and FL rats. Scale bars, $1 \mathrm{~mm}$. Ipsi, Ipsilateral; Contra, contralateral. $\boldsymbol{B}$, Percentage of TH optical density loss compared with contralateral side. The measure was made blindly using NIH Image J software. The graph shows highly significant differences between $\mathrm{FL}(n=13)$ and PL $(n=12)$ versus sham-operated $(n=12)$ rats. Moreover, significant differences were seen between the PL and FL groups. Values were expressed as the group mean \pm SE with ${ }^{* *} p<0.01$ and ${ }^{* * *} p<0.001$.

vated groups, FL and PL rats, as well as the motor pattern of sham-operated animals were analyzed using the stepping test as a well-defined motor task for forelimb akinesia (Fig. 1C). The score of the stepping test at week 2 was significantly lower in FL and PL animals ( $3 \pm 0.5$ and $8.5 \pm 2.3$, respectively) compared with sham-operated rats $(29.4 \pm 2.3)\left({ }^{* * *} p<0.001\right.$ for both groups). Moreover, a significant difference between FL and PL animals was found $\left({ }^{* * *} p<0.001\right)$, showing that PL rats had a less severe motor impairment than FL rats (Fig. 1C). Animals with a low number of turns $(<10)$ and a normal stepping test were removed from the study $(n=2)$.

According to studies showing a good correlation between motor performances and degree of DA denervation (Henderson et al., 2003; Truong et al., 2006; Paillé et al., 2007), the two experimental groups (FL and PL animals) displayed a homogeneous motor behavior. The exact quantification of the DA denervation was achieved using an immunohistochemical analysis of the $\mathrm{TH}$ expression in SNc. The amount of neurons was expressed as a percentage compared with the contralateral side (evaluated using an unbiased optical fractionator technique) (Fig. $1 D$ ). In the SNc, there were highly significant differences between FL $(n=7$, $99.4 \pm 0.3 \%)$ and PL $(n=10,74.3 \pm 6.6 \%)$ animals compared with sham-operated rats $(n=10,1.3 \pm 1.5 \%)$ and between FL vs PL animals (Fig. $1 E,{ }^{* *} p<0.001$ for both groups). DA denervation was also analyzed in the striatum. In all FL and PL rats, TH immunolabeling showed a dense innervation throughout the striatal complex in the intact side (Fig. 2A). A highly significant difference was found between FL $(n=13,99.1 \pm 0.8 \%)$ and sham-operated $(n=12,3.5 \pm 3.6 \%, p<0.001)$ animals, as well as between PL $(n=12,75.6 \pm 4.6 \%)$ and sham-operated $\left({ }^{* * *} p<\right.$ $0.001)$ rats. Furthermore, a significant difference was observed between FL and PL rats (Fig. $2 B,{ }^{* *} p<0.01$ ).

\section{Effects of partial and full denervation on striatal LTP}

Whole-cell recordings performed in slices obtained from shamoperated animals showed that the LTP-inducing protocol caused a long-lasting potentiation in all the recorded spiny neurons both in current-clamp (Fig. $3 A$, left) and voltage-clamp (Fig. $3 a$, right, $n=10$ for each experimental condition) mode. As demonstrated previously (Centonze et al., 1999), neurons obtained from FL striata fail to express LTP. Here we confirm and extend these results by performing whole-cell patch-clamp recordings in both current-clamp (Fig. 3B, open circles) and voltage-clamp (Fig. $3 C$, open circles) mode. Interestingly, the protocol used to induce LTP in normal animals only induced short-term potentiation in slices from PL animals (FL, open circles, $n=10$ for both currentand voltage-clamp experiments; PL, filled circles, $n=15$ for both current- and voltage-clamp experiments; ${ }^{\star} p<0.05$, ${ }^{* * *} p<$ $0.001)$.

To further address this issue with long recording times (up to 60 min after tetanus) not affected by the cellular dialysis associated with the whole-cell recording technique, we also performed similar experiments using sharp electrode recordings (in currentclamp mode). Under this experimental condition, HFS of corticostriatal fibers induced LTP in spiny neurons recorded from sham-operated rats (Fig. $3 D$, open squares, $n=5$ ) but not from FL animals (open circles, $n=6 ; p<0.001$ between FL vs sham 2-60 min after HFS). As observed with whole-cell recordings, in neurons recorded from PL animals (filled circles, $n=7$ ), only a transient synaptic potentiation was induced by HFS, confirming that in this model of early PD the maintenance of LTP is selectively affected $\left({ }^{* *} p<0.01\right.$ between PL vs sham-operated, from 35 min after HFS). Accordingly, no differences between FL and PL after 30 min after HFS were observed ( ${ }^{\#} p<0.05$ at $25 \mathrm{~min}$; ${ }^{\# \#} p<$ 0.01 at 10 and $20 \mathrm{~min} ;{ }^{\# \#} p<0.001$ at $15 \mathrm{~min}$ ).

\section{Effects of partial and full denervation on striatal LTD}

The effects of partial versus full DA denervation on striatal LTD were also investigated. As demonstrated previously in untreated animals (Calabresi et al., 1992; Gerdeman et al., 2002; Wang et al., 2006), current- and voltage-clamp whole-cell recordings (Fig. $4 A, n=10$ for both experimental group) as well as intracellular recordings with sharp electrodes (Fig. $4 B, n=7$ ) showed that HFS induced LTD in all the recorded neurons in slices obtained from sham-operated animals. Notably, LTD amplitude and time course were comparable in neurons recorded with whole-cell and intracellular recording techniques. In some experiments, performed in voltage-clamp mode, electrodes were filled with a $\mathrm{Cs}^{+}$based internal solution to ensure limited shunting and that cells were properly clamped. These additional experiments confirmed the possibility to induce LTD in all the recorded cells (see supplemental Fig. 1, $n=10$, available at www.jneurosci.org as supplemental material). Given these results and considering the advantages of sharp electrode recordings, which make this technique more suitable for prolonged experiments involving intracellular second-messenger pathways, we used this technique to investigate whether partial lesions affected LTD. Although LTD was completely absent in spiny neurons recorded from the FL group $\left({ }^{* *} p<0.001\right.$ between FL vs sham-operated animals), the PL group expressed LTD with amplitude and time course identi- 
A
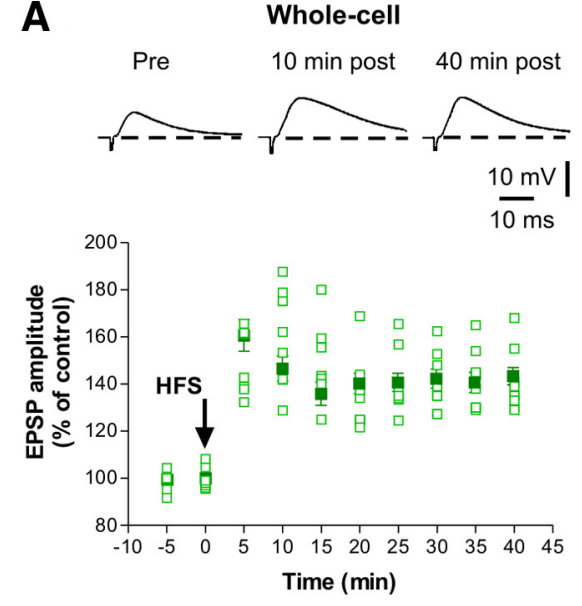

B
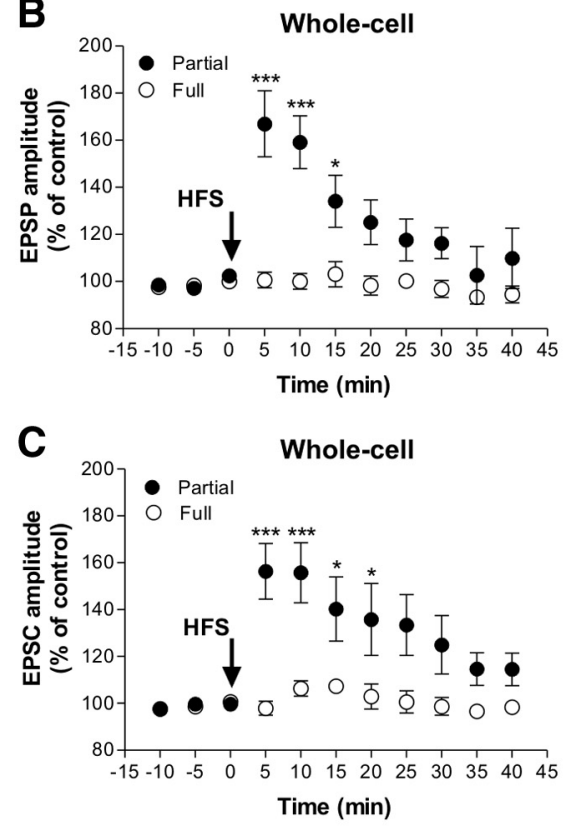

D

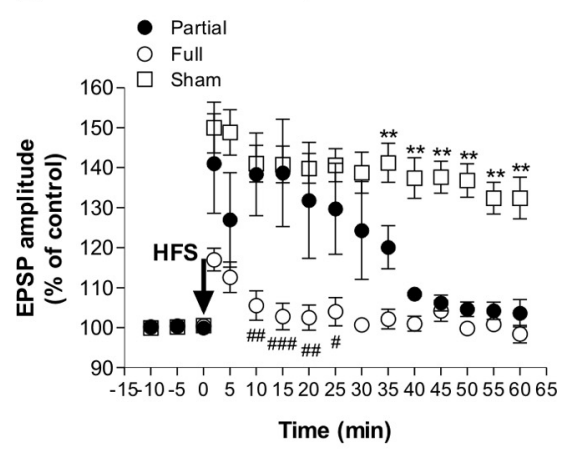

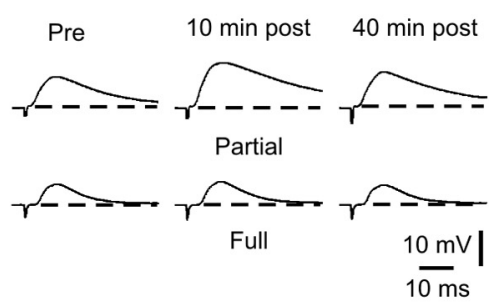
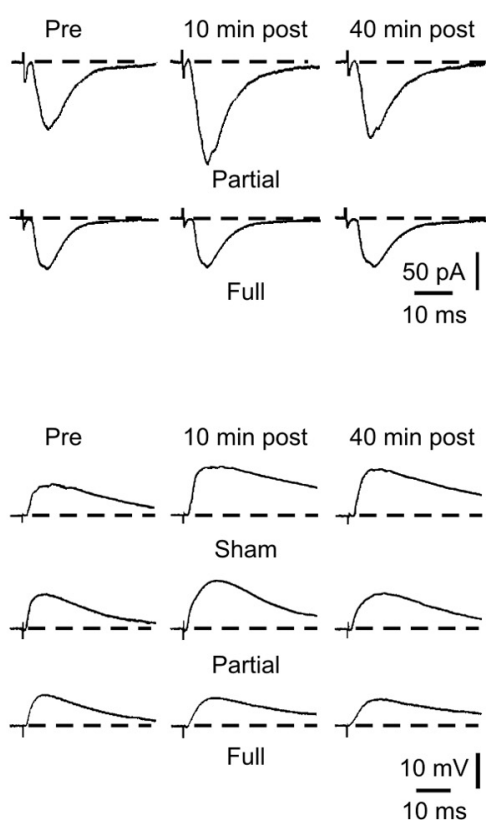

Figure 3. Altered striatal synaptic LTP in PL rats. $A$, In whole-cell configuration, in both current-clamp (left) and voltage-clamp (right) mode, all the neurons recorded displayed LTP after the application of the HFS protocol (arrow). The plots show the excitatory postsynaptic responses of striatal spiny neurons ( $n=10$ for each experimental condition) recorded in both current- and voltageclamp mode and the superimposed average of all the experiments (filled symbols). In both current-clamp $(\boldsymbol{B})$ and voltage-clamp (C) mode, the spiny neurons recorded from FL rats (open circles; $n=10$ for both current and voltage experimental group) did not express LTP. Conversely, HFS of corticostriatal fibers induced a short-term potentiation in the neurons recorded from PL rats (filled circles; $n=15$ for both experimental group) in both current- and voltage-clamp mode recordings. Values were expressed as the group mean \pm SE with ${ }^{*} p<0.05$ and ${ }^{* * *} p<0.001$. D, Using intracellular sharp electrode recordings, HFS of corticostriatal fibers induced LTP in spiny neurons from sham-operated rats (open squares; $n=5$ ) but not from FL animals (open circles; $n=6$ ). In PL animals (filled circles; $n=7$ ), only a transient LTP was observed compared with sham-operated rats (** $p<0.01$ PL vs shamoperated rats). Consistently, no differences between FL and PL after 30 min after HFS were observed ( ${ }^{\#} p<0.05$ at $25 \mathrm{~min}$; ${ }^{\# \#} p<$

cal to those seen in sham-operated animals (Fig. $4 B, n=7$ in each group). This latter observation suggests that, unlike LTP, the induction and maintenance of striatal LTD require a lower level of endogenous DA and that, although abnormalities of this form of synaptic plasticity characterize the late stage of PD, they may be absent in the early phase of this disease. In vitro administration of L-sulpiride (10 $\mu \mathrm{M})$ confirmed that the pharmacological blockade of $\mathrm{D}_{2}$ receptors was able to block LTD in partially lesioned rats as well as in sham-operated rats (data not shown).

Recent work using transgenic mice show two heterogeneous striatal spiny neuronal populations labeled in two major classes that identify the direct and the indirect striatonigral pathway. These two neuronal subclasses are thought to differ in their axonal targets (Gerfen et al., 1990) and in their capability to undergo LTD after HFS (Gerfen et al., 1990; Kreitzer and Malenka, 2007).

To strengthen our electrophysiological data, we performed experiments using voltage-clamp recordings from biocytininjected striatal spiny neurons followed by the staining for SP immunoreactivity as a reliable cytochemical marker for striatal spiny neurons of the direct pathway. Staining with biocytin was used as marker of the spiny neurons recorded from PL and sham-operated rats, followed by the SP immunostaining analyzed with confocal microscopy. In all the neurons, recorded from either sham or PL rats, in which we found that biocytin colocalized with SP, a robust LTD was expressed (supplemental Fig. 2, available at www.jneurosci.org as supplemental material). These morphological data confirm the possibility to induce LTD in the SPpositive spiny neurons recorded from corticostriatal slices obtained from both sham-operated and PL rats.

\section{Partial denervation selectively alters NMDA receptor composition in} the PSD

LTP requires activation of the NMDA receptors in the striatum as well as in other brain areas (Collingridge and Bliss, 1995; Malenka and Bear, 2004; Calabresi et al., 2007). Thus, the plastic abnormalities revealed after partial denervation are likely to reflect an alteration of NMDA receptor

0.01 at 10 and $20 \mathrm{~min} ;{ }^{\# \#} p<0.001$ at $\left.15 \mathrm{~min}\right)$. Traces represent the average of eight consecutive EPSPs or EPSCs recorded at different times. Values are expressed as the group mean $\pm \mathrm{SE}$. 
complex and signaling. Levels of NMDA receptor subunits and other PSD-associated proteins were measured in purified TIFs enriched in PSD proteins (Gardoni et al., 2001, 2006; Picconi et al., 2004) from striatum of sham-operated, FL, and PL rats by WB analysis ( $n=4$ in each group). Levels of the NMDA receptor subunit NR1 and $\alpha$ CaMKII were not altered in striatal TIFs in either FL or PL animals, suggesting that the gross composition of TIFs is not affected by different levels of DA denervation.

As reported previously (Picconi et al., 2004; Gardoni et al., 2006), the levels of NR2B subunits were specifically reduced in TIF purified from FL animals when compared with sham-operated rats without a parallel alteration of NR1 and NR2A in the same samples (Fig. $5 A, B$ ). In PL animals, the level of NR2B subunit in TIF was normal. However, PL animals were characterized by a dramatic increase in the NR2A immunostaining in the TIF ( $p=$ 0.007 compared with FL and $p=0.002$ compared with sham-operated), suggesting the presence of a profound rearrangement of the NMDA receptor composition compared with sham-operated rats (Fig. $5 A, B)$. These profound differences in NMDA receptors in the postsynaptic compartment of PL rats suggest that NR2type regulatory subunits are sensitive to plastic changes induced by the differential degree of DA denervation. NMDA receptor subunits NR2A and NR2B interact with MAGUK; this interaction governs their trafficking and clustering at synaptic sites (Kim and Sheng, 2004). Thus, we tested whether alterations in the synaptic abundance of NR2A and NR2B found in parkinsonian animals entail abnormalities of their interaction with MAGUK members (Fig. 5A, B). Analysis of PSD-95, SAP97, and SAP102 in the postsynaptic compartment revealed a significant reduction of the three proteins in FL rats compared with sham-operated rats as reported previously (Gardoni et al., 2006). In contrast, in PL rats, the level of these proteins was the same as in the sham-operated animals, suggesting that in this model of "early" PD no alteration of MAGUK protein distribution at the synapse is present. Furthermore, coimmunoprecipitation studies performed in the homogenate fraction show a dramatic increase of NR2A binding to PSD-95 in PL compared with sham-operated rats (see Fig. 7C, left panels, $+98.1 \pm 21.5 \%, p<0.005$ ). As reported previously (Gardoni et al., 2006), no modification of NR2A-PSD-95 coprecipitation was found in FL compared with sham-operated rats (data not shown). These data suggest that the NR2A subunit level at the synaptic site is a major player in early phases of PD and it is sensitive to distinct degrees of DA denervation; thus, it may represent an adequate target for early therapeutic intervention.

\section{Characterization of NMDAR/AMPAR ratio and NMDA kinetics in PL rats}

To examine possible qualitative and/or quantitative electrophysiological differences in synaptic NMDA receptors in PL rats, as suggested by biochemical data, we measured the ratio of NMDA (peak current, $V_{\text {hold }}$ of $+40 \mathrm{mV}$ ) to AMPA receptor-mediated synaptic currents (peak current, $V_{\text {hold }}$ of $-70 \mathrm{mV}$ ). Surprisingly, no significant differences were observed in either NMDA to AMPA (supplemental Fig. $3 A$, sham $0.38 \pm 0.16$ vs PL $0.34 \pm 0.2$, $p>0.05 n=9$ for each group; available at www.jneurosci.org as supplemental material) or selectively in the NMDA-NR2A/ AMPA ratios (supplemental Fig. $3 B$, sham $0.162 \pm 0.08$ vs PL $0.19 \pm 0.1, p>0.05$ respectively $n=9$ and $n=7$; available at www.jneurosci.org as supplemental material). It is well known that the kinetics of NMDAR currents are determined by receptor subunit composition (for review, see Dingledine et al., 1999). In particular, NR2B/C/D-subunit-containing receptors exhibit slower decay rates than those containing NR2A subunits (Vicini et al., 1998). Therefore, we analyzed the decay kinetics of NMDA receptors, with a double-exponential fit placed from peak to 1000 ms. One-way ANOVA demonstrated no significant differences $(p>0.05)$ in $\tau$ weighted decay constant ( $\operatorname{sham} \tau_{\mathrm{w}}=262.66 \pm$ $17.32 \mathrm{~ms}$ vs PL $\tau_{\mathrm{w}}=229.24 \pm 33.33 \mathrm{~ms}$; for each group, $n=7$ ) or in $\tau$ fast (sham $77.06 \pm 8.57 \mathrm{~ms}$ vs PL $75.19 \pm 9.14 \mathrm{~ms}$ ) and $\tau$ slow (sham $396.09 \pm 25.53 \mathrm{~ms}$ vs PL $383.70 \pm 53.77 \mathrm{~ms}$ ) between groups.

Altogether, these results may suggest that, at least in our experimental condition, we were not able to observe any modifications in the NMDA receptor currents. Although this finding is in apparent contrast with the biochemical data, one should keep in mind that whole-cell recordings allow primarily somatic mea- 
A
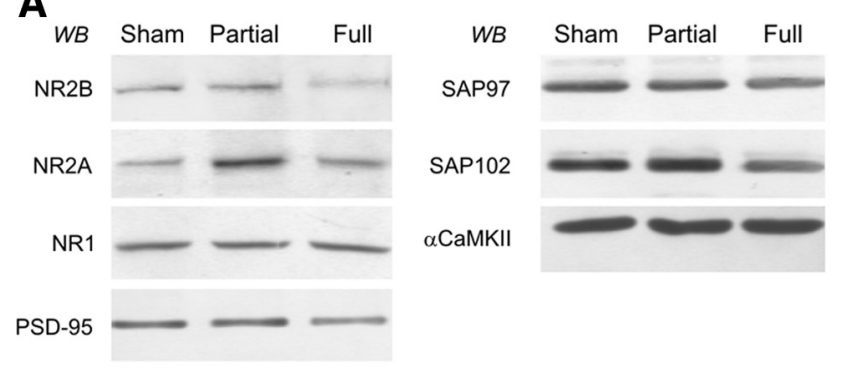

B

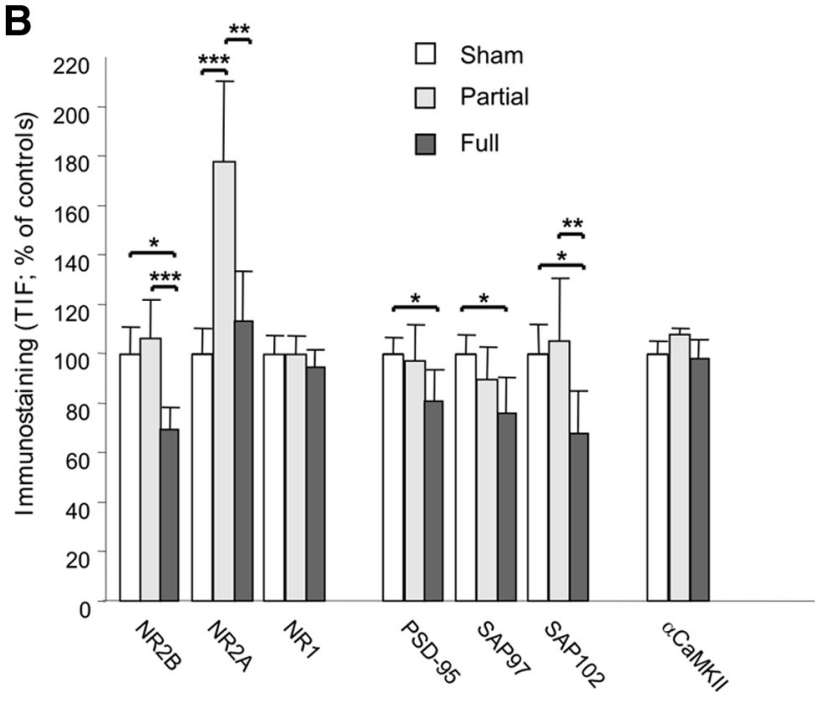

Figure 5. Composition of the NMDA receptor complex in sham-operated rats versus $P L$ and FL animals. A, Striatal homogenates and TIF from sham-operated, PL, and FL rats were analyzed by WB analysis with NR1, NR2A, NR2B, PSD-95, SAP97, SAP102, and CaMKII antibodies. The same amount of protein was loaded per lane. $\boldsymbol{B}$, Histograms show the quantification of Western blotting for all proteins performed in the TIF material. NR2B, ${ }^{*} p<0.05$ sham versus FL and ${ }^{* * *} p<0.001 \mathrm{PL}$ versus $\mathrm{FL}$; NR2A, ${ }^{* * *} p<0.001$ sham versus $\mathrm{PL}$ and ${ }^{* *} p<0.01 \mathrm{PL}$ versus $\mathrm{FL}$; PSD-95, ${ }^{*} p<0.05$ sham versus FL; SAP97, ${ }^{*} p<0.05$ sham versus FL; SAP102, ${ }^{*} p<0.05$ sham versus $\mathrm{FL}$ and ${ }^{* *} p<0.01 \mathrm{PL}$ versus $\mathrm{FL} ; n=4$ in each group.

surements and it is possible that electrophysiological changes selectively occurring in distal synaptic dendritic region are not detected by somatic recordings.

\section{Systemic administration of the $D_{1}$ agonist SKF38393 normalizes both LTP and motor behavior in early PD via the rebalance of NR2A/NR2B ratio}

Our results suggest that intermediate levels of DA availability lead to elevated NR2A expression and consequently to loss of physiological LTP. Dopamine $\mathrm{D}_{1}$-like receptors are critically required for the induction of LTP in the striatum (Centonze et al., 1999; Calabresi et al., 2000b). Moreover, $\mathrm{D}_{1}$ receptors interact through their carboxyl tail with NMDA receptor subunit NR2A (Lee et al., 2002). For these reasons, we performed a set of experiments in which we investigated the possibility to normalize NMDA receptor subunit composition and striatal LTP, as well as to improve motor performances, by directly targeting $\mathrm{D}_{1}$ DA receptors in $\mathrm{PL}$ rats. First, we analyzed the synaptic levels of $\mathrm{D}_{1}$ receptors in sham, $\mathrm{PL}$, and FL animals. Interestingly, only FL but not PL animals showed a significant reduction of $\mathrm{D}_{1}$ receptor in the TIF $\left({ }^{*} p<\right.$ $0.005 \mathrm{FL}$ vs sham) (supplemental Fig. 4, available at www. jneurosci.org as supplemental material). Then, we performed a set of experiments using in vivo administration of the dopaminergic $\mathrm{D}_{1}$-selective agonist SKF38393 in PL and sham-operated animals. In particular, we analyzed the behavioral effect of systemic injection of a low dose of SKF38393 (Olsson et al., 1995), chosen to be subthreshold for induction of rotation, administered intraperitoneally to PL animals. SKF38393 (2 mg/kg, i.p.) administration significantly improved PL rat motor performance $\left(n=4,{ }^{* *} p<0.01\right)$ (Fig. $\left.6 A\right)$. Figure $6 B$ shows the electrophysiological restoration of a long-lasting potentiation recorded from PL rats treated previously in vivo with the $\mathrm{D}_{1}$ agonist (filled diamonds; $n=5$ ) compared with that one recorded in shamlesioned rats (open squares; $n=5$ ). Conversely, the saline treatment of PL rats failed to rescue LTP (open diamonds; $n=5$ ) $\left({ }^{* *} p<0.01,{ }^{* * *} p<0.001\right.$, PL plus SKF38393 vs PL plus saline). Administration in vivo of SKF38393 did not alter the physiological LTP recorded from control animals ( $n=6$; data not shown). The molecular analysis of NMDA receptor composition in synaptic compartment confirmed the role of NR2A level normalization at synaptic sites underlying this motor restoration. In fact, WB analysis performed in the TIF preparation showed a significant decrease of NR2A subunits in the PL rats in vivo treated with SKF38393 $\left({ }^{* *} p<0.01\right)$ (Fig. $\left.6 C, D\right)$ in the absence of any significant modification of NR2B, PSD-95, and $\alpha$ CaMKII staining.

\section{"Rebalance" of NMDA receptor subunits by systemic administration of TAT2A peptide normalizes both LTP and motor behavior in early PD}

The single administration of a $\mathrm{D}_{1}$ receptor agonist was able, in our experimental setting, to restore striatal LTP, normalize NMDA receptor subunit composition, and improve motor performances in PL animals. However, it is well known that an early and long-term treatment with drugs acting at the $D_{1}$ receptor could be potentially harmful in clinical practice because these drugs could be associated with the development of dyskinesia through the stimulation of the $\mathrm{D}_{1} / \mathrm{PKA} / \mathrm{DARPP}-32$ pathway (Picconi et al., 2003; Calabresi et al., 2008; Jenner, 2008). Because the observed therapeutic effect of the $\mathrm{D}_{1}$ receptor agonist was found to be associated with a normalization of NMDA NR2A subunits in the striatum, we investigated the possibility to obtain the same therapeutic effect by directly targeting these specific subunits, to achieve a clinical benefit and, at the same time, to avoid the risks associated with the long-term modulation of the DA system. Previous reports have clearly addressed the capability of cell-permeable TAT peptides fused to the C-terminal domain of NMDA receptor subunits to reach and to disrupt NMDA/ MAGUK association both in in vitro and in vivo studies (Aarts et al., 2002; Gardoni et al., 2006). Thus, we have investigated whether the exposure to a TAT peptide (YGRKKRRQRRR) fused to the last C-terminal nine amino acids of NR2A (KMPSIESDV) (TAT2A) (Aarts et al., 2002), directly targeting the PSD-95NR2A subunit interaction, could reverse motor and synaptic plasticity abnormalities in early parkinsonism.

We addressed the behavioral, electrophysiological, and molecular consequences of TAT2A administration in vivo $(3 \mathrm{nmol} / \mathrm{g}$, $1 \mathrm{ml} / \mathrm{kg}$, i.p.) (Aarts et al., 2002) in PL animals. Animals were tested before and after $5 \mathrm{~d}$ of intraperitoneal treatment with TAT2A peptide for forelimb akinesia using the stepping test (Fig. $7 A)$. Short-term treatment with TAT2A significantly improved PL rat motor performance $\left(n=8 ;{ }^{* *} p<0.01\right)$. Conversely, motor performances of sham-operated rats $(n=8)$ were not affected by the TAT2A treatment (data not shown). A functionally irrelevant peptide lacking the last C-terminal three amino acids of NR2A (TAT2A-SDV) was used as control $(n=8)$ (Fig. $7 A$ ). To fully analyze the in vivo effect of TAT uncoupling peptide, electrophysiological recordings were also performed on cortico- 
striatal slices obtained from the same group of animals. As shown in Figure 7B, the spiny neurons recorded from TAT2Atreated PL rats (filled diamonds; $n=6$ ) showed a long-lasting LTP that did not differ from the plasticity recorded from control animals (open squares; $n=5$ ). Conversely, the TAT2A-SDV failed to rescue LTP (open diamonds; $n=7 ;{ }^{* *} p<$ 0.01 and ${ }^{* *} p<0.001$ PL plus TAT2A vs PL plus TAT2A-SDV).

Figure 7, $C$ and $D$, shows that $5 \mathrm{~d}$ treatment of PL rats with TAT2A was able to significantly reduce NR2A coprecipitation with PSD-95 in striatal homogenates (Fig. 7C, left panels, $-71.9 \pm 16.4 \%, p<$ 0.01 NR2A PL plus TAT2A vs PL). No modification of NR2A interaction with other PSD-interacting proteins such as $\alpha$ CaMKII was induced by TAT2A (Fig. $7 C$, left panels, $-5.7 \pm 12.9 \%, p>0.05$ NR2A PL plus TAT2A vs PL). Furthermore, TAT2A treatment reduced NR2A abundance at the synaptic site in PL rats to control level without modifying NR2B, PSD-95, and $\alpha$ CaMKII staining (Fig. $7 C, D)$. Finally, to confirm these molecular changes on NMDA receptor subunits induced by the application of TAT2A, we have performed whole-cell patch-clamp recordings in control rats in which we measured the effect of TAT2A on the NMDA-NR2A isolated evoked currents (supplemental Fig. 5, available at www. jneurosci.org as supplemental material). The application for $10 \mathrm{~min}$ of $300 \mathrm{~nm}$ TAT2A significantly reduced the amplitude of the NR2A isolated EPSCs (control $102.3 \pm 2.43$ vs in TAT2A $\left.68.16 \pm 3, n=4,{ }^{* *} p<0.001\right)$.

\section{Discussion}

The natural history of PD is complex and involves differential mechanisms during its various clinical phases. Most of the evidence on pathogenic pathways in PD has been obtained using experimental models of complete striatal DA depletion mimicking advanced PD. Here we describe a model of partial dopaminergic denervation mimicking the early stage of PD. Our study has profound physiological implications for the role of endogenous DA on striatal synaptic plasticity. This study, in fact, represents the first demonstration that distinct degrees of DA denervation differentially affect the induction and maintenance of two distinct and opposite forms of corticostriatal synaptic plasticity. An incomplete nigral denervation does not affect corticostriatal LTD, which is, however, abolished by a complete lesion, suggesting that a low, although critical, level of DA is required for this form of synaptic plasticity. Conversely, an incomplete DA denervation dramatically alters the maintenance of LTP, demonstrating a critical role of this form of synaptic plasticity in the early motor parkinsonian symptoms. Accordingly, we can hypothesize that LTD is implicated in the motor abnormalities observed in the late phase of PD but not in the early stage of the disease.

Striatal spiny neurons are known to represent a heterogeneous population in terms of DA receptor expression. The prevailing view is that $D_{1}$ and $D_{2}$ receptors are segregated into two subpopulations of projecting GABAergic spiny neurons, forming two large efferent streams that are thought to differ in their axonal targets (Gerfen et al., 1990). It has been recently shown that LTD might be segregated in only one of these two pathways (Kreitzer and Malenka, 2007). This hypothesis is in apparent contrast with the results of the present study and previous works from our and other groups (Calabresi et al., 1992, 1997, 2000b; Lovinger et al., 1993; Fino et al., 2005) suggesting that LTD is inducible in the large majority of striatal spiny neurons rather than only in half of them. In the present study, we confirm that, independently from the experimental approach used (whole-cell vs sharp electrode recordings), HFS-induced LTD and LTP are expressed by the large majority of striatal spiny neurons. Our electrophysiological data combined with the immunostaining of the recorded neurons further confirm that LTD is expressed not only in the spiny neurons of the indirect pathway but also in cells positive for Substance $P$, a neurochemical marker of the neurons from which the direct pathway originates. Accordingly, Wang et al. (2006) have demonstrated that, in bacterial artificial chromosome transgenic mice in which spiny neurons expressing $\mathrm{D}_{1}$ and $\mathrm{D}_{2}$ receptors are labeled with enhanced green fluorescent protein, a $\mathrm{D}_{2}$ receptor-dependent LTD is inducible in both $\mathrm{D}_{2}$ receptorexpressing and $\mathrm{D}_{1}$ receptor-expressing striatal spiny neurons. Moreover, a recent study investigating striatal spike-timingdependent plasticity has shown that DA does not act alone in regulating the induction of long-term changes in excitatory glutamatergic transmission, but it operates in concert with other 


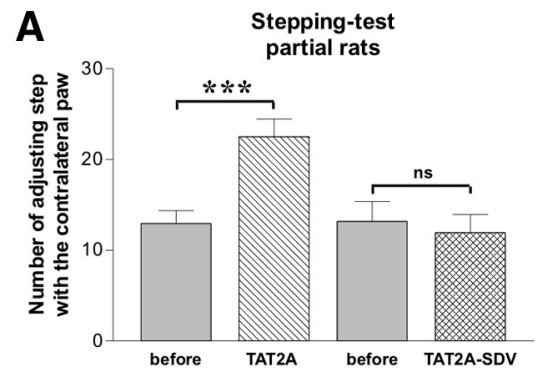

C
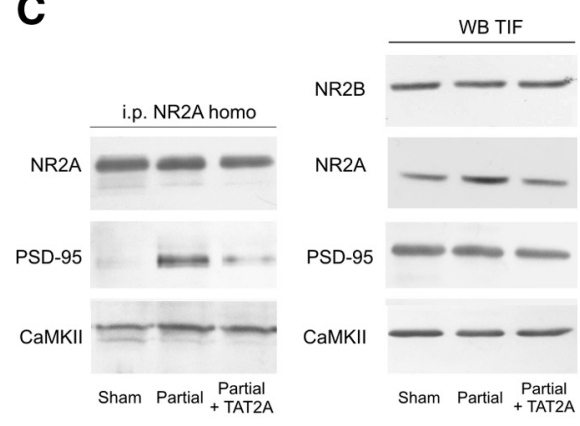

B

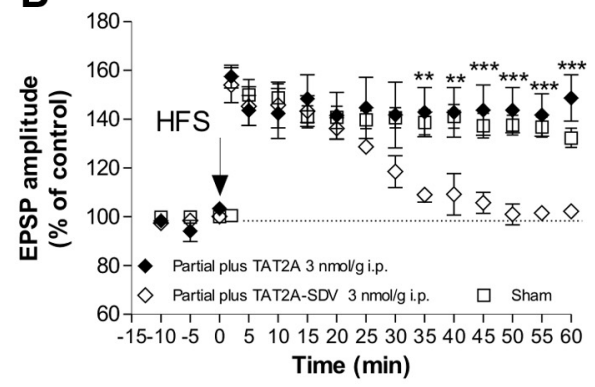

D

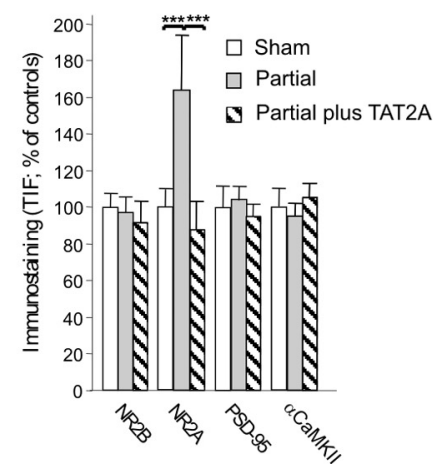

Figure 7. In vivo treatment with TAT2A improves the motor behavior and restores long-term plasticity in PL rats. $\boldsymbol{A}$, In vivo intraperitoneal injection of TAT2A $(3 \mathrm{nmol} / \mathrm{g}, 1 \mathrm{ml} / \mathrm{kg})$ improved the forelimb akinesia of PL rats after $5 \mathrm{~d}$ of treatment $(n=8$; $\left.{ }^{* * *} p<0.01\right)$. Conversely, treatment with the functionally irrelevant peptide TAT2A-SDV failed to ameliorate akinesia. $\boldsymbol{B}$, The spiny neurons recorded from TAT2A-treated PL rats showed a long-lasting LTP (filled diamonds; $n=6$ ) that did not differ from the plasticity recorded from control animals (open squares; $n=5$ ). Conversely, TAT2A-SDV failed to rescue LTP (open diamonds; $n=$ 7). Values were expressed as the group mean \pm SE with ${ }^{* *} p<0.01$ and ${ }^{* * *} p<0.001$ PL plus TAT2A versus PL plus TAT2A-SDV. C, Left, Coimmunoprecipitation of NR2A subunits of NMDA receptor with PSD-95 and CaMKIl in homogenate from sham-operated and PL animals in the absence or presence of $5 \mathrm{~d}$ treatment with TAT2A. Five days of treatment with TAT2A leads to a significant decrease in NR2A coprecipitation with PSD-95 in partial rats $(-71.9 \pm 16.4 \%, p<0.01$ NR2A PL plus TAT2A vs PL; $n=4$ in each group); no modification of NR2A interaction with other PSD-interacting proteins such as $\alpha$ CaMKII was induced by TAT2A. Right, TIF from sham-operated, PL, and PL plus TAT2A animals were analyzed by Western blot analysis with NR2B, NR2A, PSD-95, and $\alpha$ CaMKII antibodies. D, The histogram shows quantification of NR2B, NR2A, PSD-95, and $\alpha$ CaMKII in the striatal TIF in the three experimental groups. TAT2A reduced NR2A abundance at synaptic sites in partial rats to the levels found in sham-operated animals. No modification of NR2B, PSD-95, and $\alpha$ CaMKII staining in the TIF was induced by TAT2A treatment. NR2A, ${ }^{* * *} p<0.001$ sham versus $P L$ and ${ }^{* * *} p<0.001$ PL versus PL plus TAT2A.

neurotransmitters, such as adenosine (Shen et al., 2008). This evidence might in part explain the apparent discrepancies observed in different laboratories concerning the obligatory roles of $D_{1}$ and $D_{2}$ receptors in the induction of striatal synaptic plasticity.

The pathophysiological picture emerging from our data shows that the strength of glutamatergic signals from the cortex to the striatum might be dynamically regulated during the progression of the disease. In fact, bidirectional changes in corticostriatal synaptic plasticity are critically controlled by the degree of nigral denervation that influences the endogenous DA levels and the assembly of striatal NMDA receptor subunits.

From the therapeutic point of view, one of the most critical phases of the disease is represented by the early stage. In fact, the use of L-DOPA at the onset of the clinical symptoms provides beneficial effects in most of the patients. However, the early and long-term treatment with L-DOPA results in a progressively diminished pharmacological efficacy and an anticipated onset of motor complications in PD patients. In experimental models, long-term L-DOPA treatment completely disrupts bidirectional synaptic plasticity, resulting in the induction of dyskinesia (Picconi et al., 2003) associated with profound NMDA receptor subunit modification (Gardoni et al., 2006). Thus, considering the strength but also the weakness of L-DOPA treatment, particularly in the early stage of $\mathrm{PD}$, a critical question arises from our results. Is it possible to rescue both plasticity and motor activity in early PD by directly targeting the NMDA receptor complex rather than using L-DOPA?

The present study provides a possible answer to this critical question by using a model of early PD that was instrumental for the characterization of molecular, synaptic, and motor effects of a partial DA denervation. In this model of early PD, we observed mild motor symptoms: normal LTD but altered LTP associated with an increased expression of synaptic NR2A subunits. Accordingly, an uncorrected composition of NMDA receptors is a key element in both motor behavior and synaptic plasticity in the early stages of PD.

As suggested by the molecular data, obtained in PL and control rats, we analyzed qualitative and/or quantitative electrophysiological differences in the ratio of NMDAR/AMPAR-mediated synaptic currents. Surprisingly, no significant differences were observed either in NMDA to AMPA or selectively in the NMDA-NR2A to AMPA ratios. Moreover, we found no significant differences in the kinetics of NMDAR currents in PL rats compared with sham-operated rats. We therefore hypothesize that the lack of effect of the partial denervation on these electrophysiological parameters is attributable to the limitations of the use of voltage-clamp somatic recordings for the analysis of changes mainly occurring in the synaptic dendritic region. In fact, it has been suggested that this technique does not uniformly control voltage throughout the soma and dendritic tree of modeled neurons (Spruston et al., 1993; Williams and Mitchell, 2008), and thus it may be expected that one cannot appreciate fine modifications of NMDAR subunits occurring only in the postsynaptic compartment.

Moreover, here, we demonstrate that targeting $D_{1} / D_{5}$ receptors by systemic administration of SKF38393 normalizes striatal LTP, NMDA receptor subunit composition, and improves motor behavior in a model of early PD establishing a critical link among a specific subgroup of dopamine receptors, synaptic plasticity, and motor performances.

However, the long-term pulsatile stimulation of the $\mathrm{D}_{1} / \mathrm{PKA} /$ DARPP-32 pathway might lead to motor complications (Picconi et al., 2003; Calabresi et al., 2008; Jenner, 2008). For this reason, we investigated the possibility to obtain the same electrophysiological, biochemical, and behavioral effect by directly targeting NMDA receptor composition, to bypass the DA system. We have been able to demonstrate that rebalancing the composition of NMDA receptors at the synaptic site, by the systemic administration of a cell-permeable peptide, rescues PD symptoms to control levels and restore altered striatal plasticity providing a promising approach for innovative and early treatment of the disease. The possibility to target intracellular pathways and protein complexes by means of cell-permeable peptide conjugates represents a 
novel, versatile, and extremely powerful way of blocking intracellular mechanisms leading to neurodegeneration, with an unprecedented specificity and allowing for reduction of side effects. Recent data showed the possibility to use cell-permeable peptides (NR2B-C-tail) (Aarts et al., 2002) and D-JNKI1 peptide (Borsello et al., 2003) to obtain a total prevention of excitotoxicity in vitro and a powerful neuroprotection against ischemia in vivo. Here we used TAT2A peptide to compete with NR2A binding with MAGUKs. Previous findings clearly indicated that interaction with the PSD-95 member of MAGUKs enhances insertion and suppresses internalization of NR1/NR2A receptors (Lin et al., 2004), confirming the role of NR2A-C-tail-mediated interactions as important steps for the precise synaptic arrangement of NR2A-containing NMDA receptors (Steigerwald et al., 2000). In agreement with these data, here we show that a decreased NR2A interaction with PSD-95 leads to reduced NR2A abundance at synaptic sites.

Our data show that the systemic administration of TAT2A peptide holds promise as a possible treatment for the early phases of $\mathrm{PD}$, although additional experimental studies using longlasting treatments in different animal species are required to validate this approach.

\section{References}

Aarts M, Liu Y, Liu L, Besshoh S, Arundine M, Gurd JW, Wang YT, Salter MW, Tymianski M (2002) Treatment of ischemic brain damage by perturbing NMDA receptor-PSD-95 protein interactions. Science 298:846-850.

Anglade P, Mouatt-Prigent A, Agid Y, Hirsch E (1996) Synaptic plasticity in the caudate nucleus of patients with Parkinson's disease. Neurodegeneration 5:121-128.

Betarbet R, Poisik O, Sherer TB, Greenamyre JT (2004) Differential expression and ser897 phosphorylation of striatal $N$-methyl-D-aspartate receptor subunit NR1 in animal models of Parkinson's disease. Exp Neurol 187:76-85.

Borsello T, Clarke PG, Hirt L, Vercelli A, Repici M, Schorderet DF, Bogousslavsky J, Bonny C (2003) A peptide inhibitor of c-Jun N-terminal kinase protects against excitotoxicity and cerebral ischemia. Nat Med 9:1180-1186.

Calabresi P, Maj R, Pisani A, Mercuri NB, Bernardi G (1992) Long-term synaptic depression in the striatum: physiological and pharmacological characterization. J Neurosci 12:4224-4233.

Calabresi P, Saiardi A, Pisani A, Baik JH, Centonze D, Mercuri NB, Bernardi G, Borrelli E (1997) Abnormal synaptic plasticity in the striatum of mice lacking dopamine $\mathrm{D}_{2}$ receptors. J Neurosci 17:4536-4544.

Calabresi P, Centonze D, Bernardi G (2000a) Electrophysiology of dopamine in normal and denervated striatal neurons. Trends Neurosci 23:S57-S63.

Calabresi P, Gubellini P, Centonze D, Picconi B, Bernardi G, Chergui K, Svenningsson P, Fienberg AA, Greengard P (2000b) Dopamine and cAMP-regulated phosphoprotein $32 \mathrm{kDa}$ controls both striatal long-term depression and long-term potentiation, opposing forms of synaptic plasticity. J Neurosci 20:8443-8451.

Calabresi P, Picconi B, Tozzi A, Di Filippo M (2007) Dopamine-mediated regulation of corticostriatal synaptic plasticity. Trends Neurosci 30:211-219.

Calabresi P, Di Filippo M, Ghiglieri V, Picconi B (2008) Molecular mechanisms underlying levodopa-induced dyskinesia. Mov Disord 23:S570-S579.

Centonze D, Gubellini P, Picconi B, Calabresi P, Giacomini P, Bernardi G (1999) Unilateral dopamine denervation blocks corticostriatal LTP. J Neurophysiol 82:3575-3579.

Choi S, Lovinger DM (1997) Decreased frequency but not amplitude of quantal synaptic responses associated with expression of corticostriatal long-term depression. J Neurosci 17:8613-8620.

Collingridge GL, Bliss TV (1995) Memories of NMDA receptors and LTP. Trends Neurosci 18:54-56.

Day M, Wang Z, Ding J, An X, Ingham CA, Shering AF, Wokosin D, Ilijic E, Sun Z, Sampson AR, Mugnaini E, Deutch AY, Sesack SR, Arbuthnott GW, Sur- meier DJ (2006) Selective elimination of glutamatergic synapses on striatopallidal neurons in Parkinson disease models. Nat Neurosci 9:251-259.

Deumens R, Blokland A, Prickaerts J (2002) Modeling Parkinson's disease in rats: an evaluation of 6-OHDA lesions of the nigrostriatal pathway. Exp Neurol 175:303-317.

Dingledine R, Borges K, Bowie D, Traynelis SF (1999) The glutamate receptor ion channels. Pharmacol Rev 51:7-61.

Fearnley JM, Lees AJ (1991) Ageing and Parkinson's disease: substantia nigra regional selectivity. Brain 114:2283-2301.

Fino E, Glowinski J, Venance L (2005) Bidirectional activity-dependent plasticity at corticostriatal synapses. J Neurosci 25:11279-11287.

Gardoni F, Schrama LH, Kamal A, Gispen WH, Cattabeni F, Di Luca M (2001) Hippocampal synaptic plasticity involves competition between $\mathrm{Ca}^{2+} /$ calmodulin-dependent protein kinase II and postsynaptic density 95 for binding to the NR2A subunit of the NMDA receptor. J Neurosci 21:1501-1509.

Gardoni F, Picconi B, Ghiglieri V, Polli F, Bagetta V, Bernardi G, Cattabeni F, Di Luca M, Calabresi P (2006) A critical interaction between NR2B and MAGUK in L-DOPA induced dyskinesia. J Neurosci 26:2914-2922.

Gerdeman GL, Ronesi J, Lovinger DM (2002) Postsynaptic endocannabinoid release is critical to long-term depression in the striatum. Nat Neurosci 5:446-451.

Gerfen CR, Engber TM, Mahan LC, Susel Z, Chase TN, Monsma FJ Jr, Sibley DR (1990) D1 and D2 dopamine receptor-regulated gene expression of striatonigral and striatopallidal neurons. Science 250:1429-1432.

German DC, Manaye KF (1993) Midbrain dopaminergic neurons (nuclei A8, A9, and A10): three-dimensional reconstruction in the rat. J Comp Neurol 331:297-309.

Henderson JM, Watson S, Halliday GM, Heinemann T, Gerlach M (2003) Relationships between various behavioural abnormalities and nigrostriatal dopamine depletion in the unilateral 6-OHDA-lesioned rat. Behav Brain Res 139:105-113.

Höglinger GU, Rizk P, Muriel MP, Duyckaerts C, Oertel WH, Caille I, Hirsch EC (2004) Dopamine depletion impairs precursor cell proliferation in Parkinson disease. Nat Neurosci 7:726-735.

Jenner P (2008) Molecular mechanisms of L-DOPA-induced dyskinesia. Nat Rev Neurosci 9:665-677.

Kim E, Sheng M (2004) PDZ domain proteins of synapses. Nat Rev Neurosci 5:771-781.

Kreitzer AC, Malenka RC (2007) Endocannabinoid-mediated rescue of striatal LTD and motor deficits in Parkinson's disease models. Nature 445:643-647.

Lang AE, Lozano AM (1998) Parkinson's disease. First of two parts. N Engl J Med 339:1044-1053.

Lee FJ, Xue S, Pei L, Vukusic B, Chéry N, Wang Y, Wang YT, Niznik HB, Yu XM, Liu F (2002) Dual regulation of NMDA receptor functions by direct protein-protein interactions with the dopamine D1 receptor. Cell 111:219-230.

Lin Y, Skeberdis VA, Francesconi A, Bennett MV, Zukin RS (2004) Postsynaptic density protein-95 regulates NMDA channel gating and surface expression. J Neurosci 24:10138-10148.

Lovinger DM, Tyler EC, Merritt A (1993) Short- and long-term synaptic depression in rat neostriatum. J Neurophysiol 70:1937-1949.

Malenka RC, Bear MF (2004) LTP and LTD: an embarrassment of riches. Neuron 44:5-21.

McCoy MK, Martinez TN, Ruhn KA, Szymkowski DE, Smith CG, Botterman BR, Tansey KE, Tansey MG (2006) Blocking soluble tumor necrosis factor signaling with dominant-negative tumor necrosis factor inhibitor attenuates loss of dopaminergic neurons in models of Parkinson's disease. J Neurosci 26:9365-9375.

Olsson M, Nikkhah G, Bentlage C, Björklund A (1995) Forelimb akinesia in the rat Parkinson model: differential effects of dopamine agonists and nigral transplants as assessed by a new stepping test. J Neurosci 15:3863-3875.

Paillé V, Henry V, Lescaudron L, Brachet P, Damier P (2007) Rat model of Parkinson's disease with bilateral motor abnormalities, reversible with levodopa, and dyskinesias. Mov Disord 22:533-539.

Paxinos G, Watson C, Pennisi M, Topple A (1985) Bregma, lambda and the interaural midpoint in stereotaxic surgery with rats of different sex, strain and weight. J Neurosci Methods 13:139-143.

Perese DA, Ulman J, Viola J, Ewing SE, Bankiewicz KS (1989) A 6-hydroxydopamine-induced selective parkinsonian rat model. Brain Res 494:285-293. 
Picconi B, Centonze D, Håkansson K, Bernardi G, Greengard P, Fisone G, Cenci MA, Calabresi P (2003) Loss of bidirectional striatal synaptic plasticity in L-DOPA-induced dyskinesia. Nat Neurosci 6:501-506.

Picconi B, Gardoni F, Centonze D, Mauceri D, Cenci MA, Bernardi G, Calabresi P, Di Luca M (2004) Abnormal $\mathrm{Ca}^{2+}$-calmodulin-dependent protein kinase II function mediates synaptic and motor deficits in experimental parkinsonism. J Neurosci 24:5283-5291.

Schwarting RK, Huston JP (1996) The unilateral 6-hydroxydopamine lesion model in behavioral brain research. Analysis of functional deficits, recovery and treatments. Prog Neurobiol 50:275-331.

Shen W, Flajolet M, Greengard P, Surmeier DJ (2008) Dichotomous dopaminergic control of striatal synaptic plasticity. Science 321:848-851.

Spruston N, Jaffe DB, Williams SH, Johnston D (1993) Voltage- and spaceclamp errors associated with the measurement of electrotonically remote synaptic events. J Neurophysiol 70:781-802.

Steigerwald F, Schulz TW, Schenker LT, Kennedy MB, Seeburg PH, Köhr G (2000) C-Terminal truncation of NR2A subunits impairs synaptic but not extrasynaptic localization of NMDA receptors. J Neurosci 20:4573-4581.
Stocca G, Vicini S (1998) Increased contribution of NR2A subunit to synaptic NMDA receptors in developing rat cortical neurons. J Physiol 507:13-24.

Tang K, Low MJ, Grandy DK, Lovinger DM (2001) Dopamine-dependent synaptic plasticity in striatum during in vivo development. Proc Natl Acad Sci U S A 98:1255-1260.

Truong L, Allbutt H, Kassiou M, Henderson JM (2006) Developing a preclinical model of Parkinson's disease: a study of behaviour in rats with graded 6-OHDA lesions. Behav Brain Res 169:1-9.

Vicini S, Wang JF, Li JH, Zhu WJ, Wang YH, Luo JH, Wolfe BB, Grayson DR (1998) Functional and pharmacological differences between recombinant $N$-methyl-D-aspartate receptors. J Neurophysiol 79:555-566.

Wang Z, Kai L, Day M, Ronesi J, Yin HH, Ding J, Tkatch T, Lovinger DM, Surmeier DJ (2006) Dopaminergic control of corticostriatal long-term synaptic depression in medium spiny neurons is mediated by cholinergic interneurons. Neuron 50:443-452.

Williams SR, Mitchell SJ (2008) Direct measurement of somatic voltage clamp errors in central neurons. Nat Neurosci 11:790-798. 